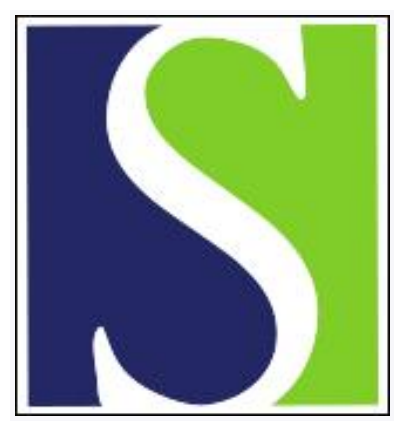

Scand J Work Environ Health 2019;45(6):529-532

https://doi.org/10.5271/sjweh.3856

Published online: 16 Oct 2019, Issue date: 01 Nov 2019

Work and mental health: what do we know and how can we intervene?

by Rugulies R, Aust B

Affiliation: National Research Centre for the Working Environment Lersø Parkallé 105, DK-2100 Copenhagen, Denmark. rer@nfa.dk

Refers to the following texts of the Journal: 2018;44(3):239-250

2017;43(6):540-549 2017;43(4):294-306 2017;43(1):50-58

2016;42(5):355-358 2006;32(6):515-527 2006;32(6):443-462

The following article refers to this text: 2022;48(3):173-189

Key terms: depression; depressive disorder; editorial; mental disorder; mental health; occupational mental health research; psychosocial

This article in PubMed: www.ncbi.nlm.nih.gov/pubmed/31616953

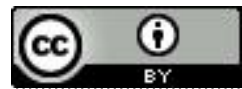




\section{Work and mental health: what do we know and how can we intervene?}

As working conditions are increasingly characterized by socio-emotional demands, interpersonal interactions and relationships, and mental requirements, at least in high-income, post-industrialized societies, work and mental health has evolved as a key topic of occupational health research $(1,2)$.

In this editorial, we focus on three main themes within this topic: (i) identifying factors at work that contribute to the onset of mental health problems and clinical mental disorders; (ii) using work as a "therapeutic tool" for individuals with mental health problems; and (iii) conducting and evaluating intervention studies.

Regarding the first theme, one of the earliest systematic reviews on work-related risk factors of common mental disorders was published in 2006 by Stansfeld \& Candy in this journal (3), an article that today is a "citation classic" (876 citations in Web of Science as of 6 October 2019). The authors identified job strain and effort-reward imbalance as risk factors, while acknowledging that only few studies of high quality were available (3). Today, more high quality studies are available and recent meta-analyses reported that job strain (4) and effort-reward imbalance (5) predict incident depressive disorders, corroborating the conclusion of the pioneering 2006 review. Other reviews suggest that also low job control (6), workplace bullying (6), and job insecurity (7) may be involved in the etiology of depressive disorders. Long working hours are also discussed, however, a recent review reported that associations between long working hours and depressive symptoms were relatively small and differed between world regions (8). Currently, the World Health Organization (WHO) and the International Labour Organization (ILO) are working on parameters for estimating the global burden of depressive disorders attributable to long working hours (9).

Despite this progress in research, important challenges remain, for example the overreliance on traditional cohort studies with one baseline and one follow-up measure only, and on self-reported measures of working conditions that may be affected by undetected prevalent mental health problems (10). Recent studies, using multiple exposure measures with fixed-effects analyses (11) or job exposure matrices (12) have started to address these challenges. Further, more research is needed on mental disorders other than depressive disorders, such as anxiety or adjustment disorders (10).

Regarding the second theme - work as a therapeutic tool - a key publication was the report by Dame Carol Black for the British Government in 2008 on "Working for a healthier tomorrow" (13). ${ }^{1}$ The report argued that "work which is appropriate to an individual's knowledge, skills and circumstances, and undertaken in a safe, healthy and supportive working environment, promotes good physical and mental health, helps to prevent ill-health and can play an active part in helping people recover from illness" (13, p67). Results from observational studies have confirmed the association between employment and better mental health (15), however, it remains unclear if being employed and re-employed influences mental health, or if better mental health increases chances for work retention and re-employment. A recent review on re-employment programs reported "some indications that re-employment programmes [...] had a positive effect on quality of life" but found "no evidence for benefits concerning mental health and functioning", thus questioning the results from the observational studies (16). In an attempt to disentangle selection and causation, Schuring et al (17) used a combination of fixed and random effects models to analyze observational data on re-employment of Dutch residents diagnosed with a mental disorder. The results indicated both selection and causation effects, with the reservations that only a small fraction of the study participants actually returned to work ( $8 \%$ ) and that confounding by time-varying confounders could not be ruled out (17).

1 In the literature, the report is often referred to as the "Black report", which is confusing, as the groundbreaking documentation of social inequalities in health in the United Kingdom, published in 1980 from a research working group chaired by Sir Douglas Black, is traditionally known as the "Black report" (14). 
Regarding the third theme-intervention studies aiming to protect and enhance workers' mental health - little is known about the key for success. It is therefore welcomed that in this issue of the Scandinavian Journal of Work, Environment and Health, three reviews either solely or partly focus on this topic.

Phillips and colleagues identified 50 randomized controlled trials using e-mental health interventions, including 34 of those in meta-analyses (18). The interventions focused on making changes in the individual, with about two-thirds based on cognitive behavioral therapy. The authors reported "moderate effects on stress, insomnia and burnout and small treatment effects on depression, anxiety, well-being, and mindfulness".

Bordado Sköld and colleagues conducted a systematic review on the effect of exercise interventions at work on either psychosocial working conditions or workers' mental health (19). The 22 included studies showed large heterogeneity in terms of study design, populations, interventions and outcome measures. Consequently, the authors did not calculate pooled estimates but performed a qualitative synthesis. Some studies reported improvements in mental health scores in the intervention groups, other studies did not find any effects. Overall, the results did not provide support for the hypothesis that workplace exercise programs may be beneficial for workers' mental health. There was also no convincing effect on psychosocial working conditions.

Proper \& van Oostrom conducted a "meta-review" (a systematic review of previously published reviews) on the effect of workplace health promotion interventions on metabolic risk factors and musculoskeletal and mental health (20). They identified 23 reviews, including 9 of high quality. There was strong evidence for an effect of workplace health promotion programs on weight-related outcomes and the prevention of musculoskeletal disorders. Regarding mental health, Proper \& van Oostrom identified 6 reviews, 4 of low and 2 of high quality. The interventions included e-mental health interventions, cognitive behavior therapy, stress management, psycho-education and physical activity. The authors conclude that there was strong evidence that e-mental health and cognitive behavior techniques had a positive effect on workers' mental health, whereas the evidence for intervention on physical activity was less clear, echoing the conclusions by Phillips et al (18) and Bordado Sköld et al (19).

What do we learn from these three reviews? First, interventions based on cognitive behavior therapy, including e-mental health interventions, seem to be an effective tool for protecting and enhancing workers' mental health $(18,20)$. However, as Phillips et al noted (18), more than two-thirds of the participants in e-mental health studies were highly educated (having at least some years of university education), and jobs in knowledge-intensive occupational sectors, such as information technology, were overrepresented. Considering that mental disorders are more prevalent in individuals of lower socioeconomic position (21-23), one may be concerned that e-mental health interventions do not reach those who need help most. Further, it remains unclear if e-mental health intervention are as effective for workers with low education as they seem to be for workers with high education.

Second, exercise programs at work sometimes seem to have a positive effect on mental health and other times not $(19,20)$, thus, no clear conclusion can be drawn. The reason for these inconsistent results are unknown as exploring these reasons was beyond the scope of the reviews $(19,20)$.

Third, the interventions did not aim to change the work environment but rather the individual worker. In the review by Bordado Sköld (19) this was a given as the review was about exercise programs. But e-mental health interventions could have been about guidance for changing working conditions and workplace health promotion does not have to be limited to health behaviors and cognitive changes but could also target the work environment, as it has been proposed in the concepts of "Comprehensive Health Promotion" (24) and "Total Worker Health" ${ }^{\mathrm{T}}$ " (25). However, these type of interventions did not seem to have qualified for the review on e-mental health (18) or the meta-review on workplace health promotion (20).

A recent meta-review on "workplace interventions for common mental disorders" (26) identified - in agreement with the meta-review by Proper \& van Oostrom (20) - cognitive behavioral therapy-based stress management as the intervention with the strongest evidence for a positive effect on workers' mental health. The only effective intervention regarding working conditions and mental health identified in this review were interventions to increase worker control (eg, self-scheduling of shifts and gradual/partial retirement) (26). However, the evidence was weaker than for cognitive behavioral therapy. 
Considering the above-delineated evidence for an association between adverse working conditions and the risk of developing mental disorders (3-12) and the ongoing discussion about using work matched to one's "knowledge, skills and circumstances, and undertaken in a safe, healthy and supportive working environment" (13) as a therapeutic tool for individuals with prevalent mental health problems and disorders (13, 15-17), it is disconcerting that organizational-level, work environment interventions to protect or enhance workers' mental health seem either not to qualify for systematic reviews $(18,20)$ or, if they do, show rather weak or inconsistent results $(26,27)$.

One reason why organizational-level interventions have not shown convincing effects regarding workers' mental health may be that these type of interventions are highly dependent on the context in which they are implemented in $(28,29)$. Consequently, researchers in this field have argued for no longer only asking "What works?", but instead "What works, for whom, under what circumstances, and how?" $(30,31)$. It can be regarded as a sign of scientific progress that this question is now increasingly being posed, indicating the retreat of the idea that workplace organizational interventions can be evaluated in a similar way to those of clinical trials testing the efficaciousness of a new drug (32-34). However, the real progress that still needs to be made would be to find answers to the question "What works, for whom, under what circumstances, and how?", to report these answers in research articles, and finally to summarize these results in new types of systematic reviews and meta-analyses (35). Occupational mental health research has quite some way to go until we reach this stage.

\section{References}

1. Sennett R. The corrosion of character. The personal consequences of work in the new capitalism. New York: Norton; 1998.

2. Ehrenberg A. The weariness of the self [Originally published in 1998 in French with the title: La fatigue d'être soi - dépression et société]. Montreal: McGill-Queen's University Press; 2010.

3. Stansfeld S, Candy B. Psychosocial work environment and mental health-a meta-analytic review. Scand J Work Environ Health. 2006;32(6):443-462. https://doi.org/10.5271/sjweh.1050

4. Madsen IEH, Nyberg ST, Magnusson Hanson LL, Ferrie JE, Ahola K, Alfredsson L, et al. Job strain as a risk factor for clinical depression: systematic review and meta-analysis with additional individual participant data. Psychol Med. 2017;47(8):1342-1356. https://doi.org/10.1017/S003329171600355X

5. Rugulies R, Aust B, Madsen IEH. Effort-reward imbalance at work and risk of depressive disorders. A systematic review and metaanalysis of prospective cohort studies. Scand J Work Environ Health. 2017;43(4):294-306. https://doi.org/10.5271/sjweh.3632

6. Theorell T, Hammarström A, Aronsson G, Träskman Bendz L, Grape T, Hogstedt C, et al. A systematic review including meta-analysis of work environment and depressive symptoms. BMC Public Health. 2015;15(1):738. https://doi.org/10.1186/s12889-015-1954-4

7. Kim TJ, Knesebeck Ovd. Perceived job insecurity, unemployment and depressive symptoms: a systematic review and meta-analysis of prospective observational studies. Int Arch Occup Environ Health. 2016;89(4):561-573. https://doi.org/10.1007/s00420-015-1107-1

8. Virtanen M, Jokela M, Madsen IEH, Magnusson Hanson LL, Lallukka T, Nyberg ST, et al. Long working hours and depressive symptoms: systematic review and meta-analysis of published studies and unpublished individual participant data. Scand J Work Environ Health. 2018;44(3):239-250. https://doi.org/10.5271/sjweh.3712

9. Rugulies R, Ando E, Ayuso-Mateos JL, Bonafede M, Cabello M, Di Tecco C, et al. WHO/ILO work-related burden of disease and injury: Protocol for systematic reviews of exposure to long working hours and of the effect of exposure to long working hours on depression. Environ Int. 2019;125:515-528. https://doi.org/10.1016/j.envint.2018.11.011

10. Rugulies R, Aust B, Madsen IEH. Occupational determinants of affective disorders. In: Bültmann U, Siegrist J, editors. Handbook of disability, work and health. Handbook Series in Occupational Health Sciences. Cham, Switzerland: Springer Nature; in press.

11. Milner A, Krnjack L, LaMontagne AD. Psychosocial job quality and mental health among young workers: a fixed-effects regression analysis using 13 waves of annual data. Scand J Work Environ Health. 2017;43(1):50-58. https://doi.org/10.5271/sjweh.3608

12. Svane-Petersen AC, Holm A, Burr H, Framke E, Melchior M, Rod NH, et al. Psychosocial working conditions and depressive disorder: disentangling effects of job control from socioeconomic status using a life-course approach. Soc Psychiatry Psychiatr Epidemiol. Online First.

13. Black C. Working for a healthier tomorrow.London: TSO, 2008. Available from: https://www.gov.uk/government/publications/workingfor-a-healthier-tomorrow-work-and-health-in-britain (Accessed: 22 September 2019).

14. Macintyre S. The Black Report and beyond: what are the issues? Soc Sci Med. 1997;44(6):723-745. https://doi.org/10.1016/S02779536(96)00183-9 
15. van der Noordt M, H IJ, Droomers M, Proper KI. Health effects of employment: a systematic review of prospective studies. Occup Environ Med. 2014;71(10):730-736. https://doi.org/10.1136/oemed-2013-101891

16. van Rijn RM, Carlier BE, Schuring M, Burdorf A. Work as treatment? The effectiveness of re-employment programmes for unemployed persons with severe mental health problems on health and quality of life: a systematic review and meta-analysis. Occup Environ Med. 2016;73(4):275-279. https://doi.org/10.1136/oemed-2015-103121

17. Schuring M, Robroek SJ, Burdorf A. The benefits of paid employment among persons with common mental health problems: evidence for the selection and causation mechanism. Scand J Work Environ Health. 2017;43(6):540-549. https://doi.org/10.5271/sjweh.3675

18. Phillips EA, Gordeev VS, Schreyogg J. Effectiveness of occupational e-mental health interventions: a systematic review and metaanalysis of randomized controlled trials. Scand J Work Environ Health. 2019; 45(6):560-576.

19. Bordado Sköld M, Bayattork M, Andersen LL, Schlünssen V. Psychosocial effects of workplace exercise - A systematic review. Scand J Work Environ Health. 2019;45(6):533-545

20. Proper KI, van Oostrom SH. The effectiveness of workplace health promotion interventions on physical and mental health outcomes - a systematic review of reviews. Scand J Work Environ Health. 2019;45(6):546-559.

21. Lorant V, Deliege D, Eaton W, Robert A, Philippot P, Ansseau M. Socioeconomic inequalities in depression: a meta-analysis. Am J Epidemiol. 2003;157(2):98-112. https://doi.org/10.1093/aje/kwf182

22. Reiss F. Socioeconomic inequalities and mental health problems in children and adolescents: a systematic review. Soc Sci Med. 2013;90:24-31. https://doi.org/10.1016/j.socscimed.2013.04.026

23. Jacquet E, Robert S, Chauvin P, Menvielle G, Melchior M, Ibanez G. Social inequalities in health and mental health in France. The results of a 2010 population-based survey in Paris Metropolitan Area. PLoS One. 2018;13(9):e0203676.

24. Aust B, Ducki A. Comprehensive health promotion interventions at the workplace: Experiences with health circles in Germany. J Occup Health Psychol. 2004;9(3):258-270. https://doi.org/10.1037/1076-8998.9.3.258

25. Hammer LB, Sauter S. Total worker health and work-life stress. J Occup Environ Med. 2013;55(12 Suppl):S25-29.

26. Joyce S, Modini M, Christensen H, Mykletun A, Bryant R, Mitchell PB, et al. Workplace interventions for common mental disorders: a systematic meta-review. Psychol Med. 2016;46(4):683-697. https://doi.org/10.1017/S0033291715002408

27. Montano D, Hoven H, Siegrist J. Effects of organisational-level interventions at work on employees' health: a systematic review. BMC Public Health. 2014;14:135. https://doi.org/10.1186/1471-2458-14-135

28. Semmer NK. Job stress interventions and the organization of work. Scand J Work Environ Health. 2006;32(6):515-527. https://doi. org/10.5271/sjweh.1056

29. Fridrich A, Jenny GJ, Bauer GF. The context, process, and outcome evaluation model for organisational health interventions. Biomed Res Int. 2015;2015:414832. https://doi.org/10.1155/2015/414832

30. Pawson R, Tilley N. Realistic evaluation. London, UK: Sage; 1997.

31. Wong G, Westhorp G, Manzano A, Greenhalgh J, Jagosh J, Greenhalgh T. RAMESES II reporting standards for realist evaluations. BMC Med. 2016;14(1):96. https://doi.org/10.1186/s12916-016-0643-1

32. Kompier M, Aust B. Organizational stress management interventions: Is it the singer not the song? Scand J Work Environ Health. 2016;42(5):355-358. https://doi.org/10.5271/sjweh.3578

33. Biron C, Karanika-Murray M. Process evaluation for organizational stress and well-being interventions: Implications for theory, method, and practice. Inter J Stress Manag. 2014;21(1):85-111. https://doi.org/10.1037/a0033227

34. Burgess MG, Brough P, Biggs A, Hawkes AJ. Why interventions fail: A systematic review of occupational health psychology interventions. Inter J Stress Manag. Online First: 19 September 2019 http://dx.doi.org/10.1037/str0000144. https://doi.org/10.1037/ str0000144

35. Rivas C, Vigurs C, Cameron J, Yeo L. A realist review of which advocacy interventions work for which abused women under what circumstances. Cochrane Database Syst Rev. 2019(6).

Reiner Rugulies ${ }^{1,2,3}$ and Birgit Aust ${ }^{1}$

${ }^{1}$ National Research Centre for the Working Environment

${ }^{2}$ Department of Public Health, University of Copenhagen, Denmark

${ }^{3}$ Department of Psychology, University of Copenhagen, Denmark

Correspondence to: Reiner Rugulies, PhD, MSc, MPH

National Research Centre for the Working Environment

Lersø Parkallé 105

DK-2100 Copenhagen, Denmark. [Email: rer@nfa.dk] 